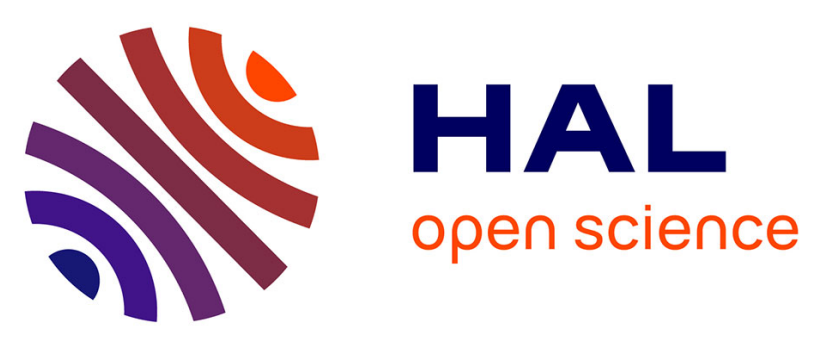

\title{
Molecular genetic contribution to the developmental course of attention-deficit hyperactivity disorder
}

\author{
Kate Langley, Tom A. Fowler, Deborah L. Grady, Robert K. Moyzis, Peter A.
}

Holmans, Marianne B. M. Bree, Michael J. Owen, Michael C. O’Donovan, Anita Thapar

\section{To cite this version:}

Kate Langley, Tom A. Fowler, Deborah L. Grady, Robert K. Moyzis, Peter A. Holmans, et al.. Molecular genetic contribution to the developmental course of attention-deficit hyperactivity disorder. European Child and Adolescent Psychiatry, 2008, 18 (1), pp.26-32. 10.1007/s00787-008-0698-4 . hal00478062

\section{HAL Id: hal-00478062 https://hal.science/hal-00478062}

Submitted on 30 Apr 2010

HAL is a multi-disciplinary open access archive for the deposit and dissemination of scientific research documents, whether they are published or not. The documents may come from teaching and research institutions in France or abroad, or from public or private research centers.
L'archive ouverte pluridisciplinaire HAL, est destinée au dépôt et à la diffusion de documents scientifiques de niveau recherche, publiés ou non, émanant des établissements d'enseignement et de recherche français ou étrangers, des laboratoires publics ou privés. 
Kate Langley

Tom A. Fowler

Deborah L. Grady

Robert K. Moyzis

Peter A. Holmans

Marianne B.M. van den Bree

Michael J. Owen

Michael C. O'Donovan

Anita Thapar
Accepted: 19 May 2008

Published online: 18 June 2008

K. Langley, Ph.D. ( $\square)$

T.A. Fowler, Ph.D.

P.A. Holmans, Ph.D.

M.B.M. van den Bree, Ph.D.

M.J. Owen, Ph.D., FRCPsych, FmedSci

M.C. O'Donovan, Ph.D., FRCPsych

A. Thapar, Ph.D., FRCPsych

Department of Psychological Medicine

School of Medicine

Cardiff University

4th Floor Main Building, Heath Park

Cardiff CF14 4XN, UK

Tel.: +44-2920/742934

Fax: +44-2920/747839

E-Mail: langleyk@cardiff.ac.uk

D.L. Grady, Ph.D. · R.K. Moyzis, Ph.D.

Department of Biological Chemistry

University of California

Irvine (CA) 92697, USA

R.K. Moyzis, Ph.D.

Institute of Genomics and Bioinformatics

University of California

Irvine (CA) 92697, USA

\section{Molecular genetic contribution to the developmental course of attention-deficit hyperactivity disorder}

Abstract Objective The developmental trajectory of attentiondeficit hyperactivity disorder (ADHD) is variable. Utilizing a longitudinally assessed sample, we investigated the contribution of susceptibility gene variants, previously implicated through pooled or meta-analyses, to the developmental course of Attention-Deficit Hyperactivity Disorder over time. Methods 151 children (aged 6-12) who met diagnostic criteria for ADHD were assessed using research diagnostic interviews during childhood and 5 years later in adolescence. Severity was defined as total number of ADHD symptoms at baseline and reassessment. Association with variants at $D R D 4$, $D R D 5$, and the dopamine transporter gene, DAT was analyzed using linear regression. Results As expected, affected individuals showed a decline in ADHD severity over time. The DRD4 $48 \mathrm{bp}$ VNTR 7-repeat and DRD5 CA(n) microsatellite marker 148 bp risk alleles were associated with persistent ADHD. Those possessing the DRD4 7 repeat risk allele showed less of a decline in severity at reassessment than those without the risk allele. Conclusions Those carrying the DRD4 7 risk allele showed greater symptom severity at follow-up and less $\mathrm{ADHD}$ reduction over time. These findings support the hypothesis that some susceptibility genes for ADHD also influence its developmental course.

Key words ADHD - longitudinal - DRD4 - DRD5 DAT1

\section{Introduction}

Attention deficit hyperactivity disorder (ADHD) is a $\infty$ highly disabling neurodevelopmental disorder affecting between 2 and $5 \%$ of the school aged population 惫 $[5,15]$. Associated with a number of negative out- comes including poor academic performance as well as impaired peer and family relationships, [3] ADHD is one of the most common reasons for referral to specialist Child Mental Health Services [23]. Most studies show some symptom decline over time, although the clinical diagnosis of ADHD is recognized to persist from childhood into adolescence and even 
adulthood in some individuals $[10,14]$. ADHD persisting beyond childhood has been shown to be associated with increased negative sequelae including antisocial behavior, and lower academic and occupational achievement levels [14]. Thus, the developmental course of ADHD has important clinical implications. However little is known about the etiological factors contributing to change in ADHD severity over time [34].

There is a substantial genetic contribution to ADHD, with twin studies reporting heritability estimates of between 60 and 80\% [35]. Molecular genetic studies aimed at identifying risk gene variants for the disorder have yielded a number of replicated findings. The most widely replicated association is for a $48 \mathrm{bp}$ variable number tandem repeat (VNTR) variant within the Dopamine D4 Receptor Gene (DRD4) [12, $13,24,26]$. The second most robustly replicated finding in pooled analyses is to a simple repeat sequence polymorphism (a CA(n) microsatellite marker) flanking the Dopamine Receptor D5 Gene (DRD5) [24-26]. There are also replicated association study findings for a $480 \mathrm{bp}$ VNTR in the $3^{\prime}$ UTR (untranslated region) of the Dopamine transporter Gene (DAT1, also known as Slc6a3). However, the findings with DAT1 are less consistent, with one metaanalysis yielding a small but significant association [13] and four other meta-analyses reporting no association $[6,24,26,30]$.

It has long been recognized that ADHD is a clinically varied disorder, differing in the predominance of symptom dimensions, comorbid disorders, and the clinical course over time [3]. Longitudinal twin studies have shown a strong genetic contribution to ADHD symptom persistence [20, 22, 28, 29, 31]. As a result of these findings, it has been suggested that genes influencing ADHD susceptibility may also play a role in its temporal course [34]. ADHD which persists into adolescence and adulthood has been demonstrated to be more familial than ADHD restricted to childhood [20]. It has also been suggested that samples with a persistent form of ADHD might reduce phenotypic and possibly genetic heterogeneity, thereby increasing statistical power to detect susceptibility gene variants associated with the disorder [11].

We set out to test these hypotheses by using the most robustly associated ADHD susceptibility gene variant detected so far, namely the DRD4 7 repeat allele. Specifically, we postulated that this allele would predict a worse developmental course in terms of ADHD symptom severity, defined as the total number of ADHD symptoms present. We also conducted exploratory analyses of these associations for the somewhat less well-established genetic risk factors $D R D 5$ and DAT1. Finally, allele frequencies for those with baseline and "persistent" ADHD were compared to those of controls.

\section{Method}

British Caucasian children aged between six and twelve years, with suspected or diagnosed ADHD, were originally recruited as part of a genetic study. Child and Adolescent Psychiatrists and Paediatricians in the Greater Manchester, South Wales and Avon areas of the UK referred children to the study. The children underwent an extensive assessment, including research diagnostic interviews. Individuals were excluded if they had a full scale IQ below 70, Tourette's syndrome, Pervasive Developmental Disorder or any Neurological disorder including Epilepsy. The ethnicity of participants (as well as their parents and grandparents) was defined by the families themselves. As this is a genetic study, ethnicity was assessed to minimise genetic differences as the result of ethnic differences between participants.

The sample for this longitudinal study was drawn from an original cross-sectional study that included 375 children who met DSM-III-R/ DSM-IV criteria for ADHD or ICD-10 criteria for Hyperkinetic Disorder at baseline (mean age 9.2 years, $\mathrm{SD}=2.1$ years). If the child was taking stimulant medication, parents were interviewed regarding behaviour before medication was administered. To improve the accuracy of retrospective phenotypic measurement, participants who had been taking stimulant medication for more than a year were excluded. More detail on the original crosssectional study and its findings can be found in Holmes et al. [18], Langley et al. [21] and Whittinger et al. [37]. The baseline genetic data have since been expanded due to additional genotyping.

This current paper focuses on a new longitudinal study of ADHD that included children from the original study who had reached adolescence. Five years later, those individuals aged 12 years or over were invited to participate in a follow up study. Of 198 individuals eligible, 190 were traced and $151 \mathrm{com}$ pleted all components of reassessment $(76 \%$ of those eligible). The mean age at follow up was 14.5 years, $(\mathrm{SD}=1.7$ years $)$. Written informed consent from parents and assent from children was received at each wave of data collection. This study was reviewed and gained approval from the North West Multicentre Research Ethics Committee (UK).

\section{Measures}

At baseline, parents (typically the mother) were interviewed using the child and adolescent psychiatric 
assessment (CAPA) [2]. The CAPA is a semi structured interview which enables the presence or absence of DSM-IV, DSM-III-R and ICD-10 symptoms and diagnosis of childhood psychiatric disorders to be determined. We used this measure to assess symptoms and diagnoses of ADHD, Conduct Disorder, Oppositional Defiant Disorder and Mood disorders. For $A D H D$, parents provided information regarding the presence of each symptom. Individuals had to demonstrate sufficient parent rated symptoms of the disorder to obtain a diagnosis.

The presence of ADHD symptoms or impairment in school, necessary for ICD-10 and DSM-IV diagnoses of the disorder was assessed using the child ADHD teacher telephone interview (ChATTI) [17]. Teacher ratings were used only to provide evidence of pervasiveness of symptoms across situations.

At follow up, parents and adolescents were interviewed using the CAPA-parent and child versions [1, 2] regardless of medication status. The teacher ChATTI was again completed to ascertain symptoms in a school setting. From this information, we generated a diagnostic subgroup of adolescents with "persistent" ADHD who continued to meet full DSMIV diagnostic criteria for ADHD at follow up $(n=93$, $62 \%)$.

All interviewers were trained in house to a high standard through intensive training by a child psychiatrist with extensive experience of the CAPA (AT) and by weekly supervision meetings by the same individual. High rates of inter-rater reliability between Time 1 and Time 2 were achieved with $\kappa$ coefficients of 1.00 for diagnoses of ADHD.

\section{Genotyping information}

DNA was extracted by phenol chlorophorm extraction from venous blood or buccal mouthwash samples. Genotyping of each of these markers has been described in previous publications and was blind to phenotypic status with respect to the measures presented in this paper. Briefly, genotyping of the DAT1 $480 \mathrm{bp}$ VNTR was performed using primers and conditions described by Daly and colleagues [7] as detailed in Holmes and colleagues [19] The DRD5 $\mathrm{CA}(\mathrm{n})$ microsatellite marker was genotyped on an ABI 3100 capillary sequencer according to the primers and conditions described by Sherrington and colleagues [33]. For the DRD4 $48 \mathrm{bp}$ VNTR, primer sets and analyses described previously were used $[8,16,36]$. For some samples, adjacent SNPs known to be in strong linkage disequilibrium with the $D R D 47 \mathrm{R}$ VNTR $[8,36]$ were analyzed to confirm the genotype.

\section{Control sample}

Control data, previously utilised in studies of these gene variants were available from the UK Blood Transfusion Service and General Practice Registers. All individuals were of British Caucasian origin. No additional demographic or clinical information, was available. For DRD4 [19] data from 442 controls were available, for DRD5 data from 97 controls [38] and for $D A T 1$, there were data for 295 controls [19].

\section{Data analysis}

For analysis of change in ADHD severity over time, linear regression analysis was performed with risk genotype as the independent variable and total number of DSM-IV ADHD symptoms at reassessment as the dependent variable, controlling for total number of DSM-IV ADHD symptoms at baseline. Where univariate analyses were found to be significant, analyses were repeated controlling for the significant covariates of age, sex, current DSM-IV conduct disorder symptoms and medication. All independent variables, including ADHD symptoms at baseline and follow up, as well as all linear covariates were normally distributed. Allele frequencies for those with baseline ADHD (all individuals) and "persistent" cases were compared to those for controls using analysis of $2 \times 2$ contingency tables. Individuals were classified as being "at risk" for a certain risk variant if they possessed; one or more DRD4 48 bp VNTR 7repeat allele; one or more DRD5 (CA)n microsatellite $148 \mathrm{bp}$ marker; and two copies of the DAT1 $480 \mathrm{bp}$ VNTR 10-repeat allele.

\section{Results}

At follow up, 93 participants (62\%) continued to meet full diagnostic criteria for DSM-IV ADHD. 69\% $(n=64)$ of individuals with a diagnosis at Time 2 retained the same subtype diagnosis from Time 1 with the majority of those who changed subtype moving from Combined to either Inattentive or HyperactiveImpulsive subtype. There were no significant differences for baseline measures of gender, number of ADHD, ODD or conduct disorder symptoms, between those individuals who participated in the follow up study $(n=151)$ and those who were eligible but did not participate $(n=47)$, although there was a trend for participants to be slightly younger $(t=1.88$, $P=0.06)$. The distributions of all variants for both ADHD participants and control groups were in Hardy Weinberg equilibrium. 
The mean number of DSM-IV ADHD symptoms at baseline was $14.7(\mathrm{SD}=2.4)$ and $12.2(\mathrm{SD}=4.8)$ at follow up. The mean ADHD symptom decline was $-2.5(\mathrm{SD}=4.6)$. This difference was statistically significant $(\beta=0.35, t=4.53, P \leq 0.001)$. All data were normally distributed. At baseline, 23 individuals (15\%) met diagnostic criteria for DSM-IV conduct disorder. At follow up 46 individuals (31\%) met such criteria.

\section{Change in ADHD severity over time}

The DRD4 48 bp VNTR predicted the total number of DSM-IV ADHD symptoms at follow up controlling for total symptoms at baseline, even when the covariates of age, gender and current conduct disorder symptoms were taken into account $\left(r^{2}\right.$ change $=0.04$, $\beta=0.20, t=2.53, P=0.01)$. The mean reduction in ADHD symptoms also illustrated poorer prognosis for those with the DRD4 7 repeat variant; those carrying the 7 repeat allele showing a mean reduction of 1.4 symptoms $(\mathrm{SD}=3.7$ ), those without the 7 repeat allele showing a mean reduction of 3.3 symptoms $(\mathrm{SD}=4.5)$. The magnitude of the association was not significantly different between baseline and follow up. The DRD5 and DAT1 gene variants did not predict ADHD symptom decline (see Table 1). Analysis of the inattentive and hyperactive-impulsive symptom dimensions separately indicated that this effect was not specific to either dimension.

\section{Genetic variants predicting ADHD persistence into adolescence}

Case-control analysis revealed significant association between the DRD4 $48 \mathrm{bp}$ VNTR 7-repeat allele and "persistent $\operatorname{ADHD}^{2}\left(\chi^{2}=15.41, \mathrm{df}=1, P \leq 0.0001\right)$. The odds ratio (OR) was 1.86 (95\% CI: 1.30, 2.65, $P=0.001)$ for diagnosis of the disorder at baseline and 2.12 (95\% CI: 1.45, 3.11, $P<0.0001)$ at follow up.
Similarly, the 148 bp risk allele of the DRD5 CA(n) microsatellite marker also significantly predicted baseline $\left(\chi^{2}=5.02, \mathrm{df}=1, P=0.02, \mathrm{OR}=1.62,95 \%\right.$ CI: $1.06,2.47)$ persistent ADHD diagnosis $\left(\chi^{2}=5.78\right.$, $\mathrm{df}=1, P=0.02, \mathrm{OR}=1.75,95 \%$ CI: $1.11,2.77)$. The DAT1 variant was not associated with persistent ADHD $\left(\chi^{2}=0.38, \quad \mathrm{df}=1, \quad P=0.54\right) \quad$ or baseline $\operatorname{ADHD}\left(\chi^{2}=0.26, \mathrm{df}=1, P=0.61\right)$.

\section{Discussion}

The DRD4 48 bp VNTR significantly influenced decline in ADHD symptoms over time, with those carrying the 7 repeat allele showing less than half the decline in symptoms of those without the allele. Our case-control analyses revealed significant associations between "persistent" ADHD and the risk alleles in DRD4 (VNTR 7 repeat) and DRD5 (148 bp allele) but not with DAT1. For both associated variants, the odds ratios were greater in the persistent ADHD sample than in those with the baseline diagnosis but the differences in magnitude of odds ratios were not significant.

These findings suggest a role for the DRD4 VNTR in the developmental course of ADHD as well as increasing susceptibility for childhood ADHD. The findings also support the hypothesis that some genes that influence ADHD will also affect its developmental course. To date, the focus of most psychiatric genetic studies has been to identify genes that increase susceptibility to specific disorders, including ADHD. Although this is an important goal, there is considerable variation in the course of psychiatric disorders such as ADHD over time. Identifying risk factors that influence the developmental course of ADHD is an additional and important aim. The risk factors and causal pathways that influence developmental course may be the same as those that increase susceptibility to onset but they could also differ [34]. Our findings support this hypothesis because the DRD4 and DRD5

Table 1 Linear regression analysis of gene variants predicting change in ADHD severity over time

\begin{tabular}{|c|c|c|c|c|c|c|}
\hline & \multirow[t]{2}{*}{$R^{2}$} & \multicolumn{2}{|c|}{ Unstandardised coefficients } & \multicolumn{3}{|c|}{ Standardised coefficients } \\
\hline & & $\beta$ & Standard error & $\beta$ & $t$ & $P$-value \\
\hline \multicolumn{7}{|l|}{ DRD4 48 bp VNTR } \\
\hline Baseline ADHD severity & 0.001 & 0.26 & 0.42 & 0.05 & 0.62 & 0.54 \\
\hline Change in ADHD severity at follow up & 0.04 & 1.72 & 0.68 & 0.20 & 2.53 & 0.01 \\
\hline \multicolumn{7}{|l|}{ DRD5 CA(n) microsatellite } \\
\hline Baseline ADHD severity & $<0.0001$ & 0.31 & 0.25 & 0.14 & 1.23 & 0.22 \\
\hline Change in ADHD severity at follow up & $<0.0001$ & -0.13 & 0.79 & -0.02 & -0.17 & 0.87 \\
\hline \multicolumn{7}{|l|}{ DAT1 480 bp VNTR } \\
\hline Baseline ADHD severity & 0.009 & -0.43 & 0.40 & -0.09 & -1.09 & 0.28 \\
\hline Change in ADHD severity at follow up & 0.002 & 0.48 & 0.74 & 0.05 & 0.65 & 0.52 \\
\hline
\end{tabular}


variants were both associated with the disorder, but only the DRD4 7-repeat allele predicted the developmental course.

Our case-control findings are in line with previous studies showing association between ADHD and the DRD4 $48 \mathrm{bp}$ VNTR and the DRD5 CA(n) microsatellite marker. The magnitude of the Odds ratios for both variants was greater for the analysis of persistent ADHD, however, unfortunately, the number of non persistent individuals at follow up $(n=58)$ was insufficient to directly compare the differences between the persistent and non persistent groups.

Identifying genetic and other risk factors that influence the developmental course of ADHD is important for several reasons. First, it is important to identify the mechanisms that lead to poorer clinical outcomes. Second, clinical resources such as intensity of follow-up ideally need to be tailored according to need. Predictors, both clinical and etiological, could thus help target resources more effectively. The identification of non-genetic factors and how they may interact with genetic variants in influencing the developmental course of ADHD is also an important area for future research, although large longitudinal samples will be needed when testing for Gene $\mathrm{x}$ Environment interactions.

To date, to the best of our knowledge there have been four other longitudinal molecular genetic studies of ADHD. Our findings regarding DRD4 are consistent with results from two of these. In the first community-based study [9] the authors also found that the influence of the DRD4 $48 \mathrm{bp}$ VNTR on diagnosis of ADHD in boys increased with age. This study, however, followed individuals only until the age of 11 years and so did not assess the impact of this variant during adolescence. It also had very small numbers of participants with an ADHD diagnosis. The second study showed association between the DRD4 7-repeat allele and worse adult psychosocial outcome [27]. The third study followed 122 ADHD participants and 67 controls across three time points during childhood, adolescence and young adulthood, did not however demonstrate an association between the DRD4 7 repeat allele and ADHD at any time point (although various associations with the DAT1 480 bp VNTR were reported) [4]. Finally, a case-control study of 67 individuals with ADHD found that possession of the 7-repeat allele was associated with better clinical outcome (retaining a diagnosis of combined type ADHD) [32]. However, this last study differed from ours in having a sample with a higher percentage of girls and higher IQ scores.

These results suggest that although the DRD4 VNTR influences symptom decline, it is not possi- ble to conclude that the DRD4 and DRD5 variants are more strongly associated with "persistent "ADHD; the group who continue to meet full diagnostic criteria at follow up. To date, there have been few molecular genetic studies of adult ADHD, but those that have been published suggest that the DRD4 7 repeat allele is also a risk allele in this age group. Thus far, there has been nothing to suggest that the effect sizes of risk gene variants are greater for adult or adolescent ADHD compared to childhood ADHD. However given our sample size we could not test for differences because of a lack of statistical power.

Although it would have been interesting to compare presence of the risk alleles between those with persistent and "non persistent" diagnoses at follow up, the number of individuals without a persistent diagnosis was too small. Moreover, although not meeting DSM-IV diagnostic criteria for ADHD at the adolescent follow up most individuals (89\% of the sample) still had ADHD symptoms and impairment (which has important clinical implications) and therefore cannot truly be categorised as "non persistent". That is, there is no clear-cut, clinically meaningful way of defining "non-persistence".

As with any study, there are a number of limitations of this design. First, the sample size for analysis was modest. Nevertheless we still found evidence of association at both time points for the most strongly implicated susceptibility gene variant, the DRD4 VNTR. This modest sample size illustrates the need for further replications of these findings in larger, diverse samples.

Second, our findings that the DRD4 7 repeat allele was associated with ADHD symptom severity at follow-up but not baseline may be considered surprising. However, as all 'cases' met diagnostic criteria for ADHD at baseline, they also all had high ADHD symptom counts in childhood (at baseline). Therefore, the range for the number of symptoms was restricted (8-18). By adolescence, the variation in symptom scores was much greater (range 0-18). Therefore, it is remains possible that that our sample of clinical cases lacked power to detect childhood ADHD severity as a result of limited variation in symptom scores. Stimulant medication may have influenced symptom severity at follow up. However, controlling for medication in the analyses did not alter the results.

In conclusion, the findings of our longitudinal genetic study of ADHD indicate that the DRD4 7 repeat allele predicted a poorer developmental course with carriers of the 7 repeat allele showing less than half the ADHD symptom decline over a five year period of those without the allele. 
Acknowledgments We would like to acknowledge the help and advice of Dr. Valentina Moskvina with the statistical analysis. Financial Support: The first wave of data collection was supported by the Wellcome Trust and ACTION research. The second wave of data was supported by the Department of Health (England). We would also like to acknowledge the support of grants from the National Institute of Mental Health (US NIH) and National Institute of Aging (US NIH) to RKM, Janssen Cilag who funded TAF and the Wellcome Trust who provided a Value in People Award for KL. The authors have no financial disclosures. AT had full access to all of the data in the study and takes responsibility for the integrity of the data and the accuracy of the data analysis.

\section{References}

1. Angold A, Costello EJ (1995) A testretest reliability study of child-reported psychiatric symptoms and diagnoses using the child and adolescent psychiatric assessment (CAPA-C). Psychol Med 25:755-762

2. Angold A, Prendergast $M$, Cox A, Harrington R, Simonoff E, Rutter M (1995) The child and adolescent psychiatric assessment (CAPA). Psychol Med 25:739-753

3. Barkley RA (1998) Attention deficit hyperactivity disorder. The Guildford Press, New York

4. Barkley RA, Smith KM, Fischer M, Navia B (2006) An examination of the behavioral and neuropsychological correlates of three ADHD candidate gene polymorphisms (DRD4 7+, DBH TaqI A2, and DAT1 40 bp VNTR) in hyperactive and normal children followed to adulthood. Am J Med Genet B Neuropsychiatr Genet 141:487-498

5. Costello EJ, Mustillo S, Erkanli A, Keeler G, Angold A (2003) Prevalence and development of psychiatric disorders in childhood and adolescence. Arch Gen Psychiatry 60:837-844

6. Curran S, Mill J, Tahir E, Kent L, Richards S, Gould A, Huckett L, Sharp J, Batten C, Fernando S, Ozbay F, Yazgan Y, Simonoff E, Thompson M, Taylor E, Asherson P (2001) Association study of a dopamine transporter polymorphism and attention deficit hyperactivity disorder in UK and Turkish samples. Mol Psychiatry 6:425-428

7. Daly G, Hawi Z, Fitzgerald M, Gill M (1999) Mapping susceptibility loci in attention deficit hyperactivity disorder: preferential transmission of parental alleles at DAT1, DBH and DRD5 to affected children. Mol Psychiatry 4:192196

8. Ding YC, Chi HC, Grady DL, Morishima A, Kidd JR, Kidd KK, Flodman P, Spence MA, Schuck S, Swanson JM, Zhang YP, Moyzis RK (2002) Evidence of positive selection acting at the human dopamine receptor D4 gene locus. Proc Natl Acad Sci USA 99:309-314
9. El-Faddagh M, Laucht M, Maras A, Vohringer L, Schmidt MH (2004) Association of dopamine D4 receptor (DRD4) gene with attention-deficit/ hyperactivity disorder (ADHD) in a high-risk community sample: a longitudinal study from birth to 11 years of age. J Neural Transm 111:883-889

10. Faraone SV, Biederman J, Mick E (2006) The age-dependent decline of attention deficit hyperactivity disorder: a meta-analysis of follow-up studies. Psychol Med 36:159-165

11. Faraone SV, Biederman J, Monuteaux MC (2000) Toward guidelines for pedigree selection in genetic studies of attention deficit hyperactivity disorder. Genet Epidemiol 18:1-16

12. Faraone SV, Doyle AE, Mick E, Biederman J (2001) Meta-analysis of the association between the 7-repeat allele of the dopamine $\mathrm{D}(4)$ receptor gene and attention deficit hyperactivity disorder. Am J Psychiatry 158:1052-1057

13. Faraone SV, Perlis RH, Doyle AE, Smoller JW, Goralnick JJ, Holmgren MA, Sklar P (2005) Molecular genetics of attention-deficit/hyperactivity disorder. Biological Psychiatry 57:13131323

14. Faraone SV, Spencer TJ, Montano CB, Biederman J (2004) Attention-deficit/ hyperactivity disorder in adults: a survey of current practice in psychiatry and primary care. Arch Intern Med 164:1221-1226

15. Ford T, Goodman R, Meltzer H (2003) The British child and adolescent mental health survey 1999: the prevalence of DSM-IV disorders. J Am Acad Child Adolesc Psychiatry 42:1203-1211

16. Grady DL, Chi HC, Ding YC, Smith M, Wang E, Schuck S, Flodman P, Spence MA, Swanson JM, Moyzis RK (2003) High prevalence of rare dopamine receptor D4 alleles in children diagnosed with attention-deficit hyperactivity disorder. Mol Psychiatry 8:536545

17. Holmes J, Lawson D, Langley K, Fitzpatrick H, Trumper A, Pay H, Harrington R, Thapar A (2004) The child attention-deficit hyperactivity disorder teacher telephone interview (CHATTI): reliability and validity. $\mathrm{Br} \mathrm{J}$ Psychiatry 184:74-78
18. Holmes J, Payton A, Barrett J, Harrington $\mathrm{R}$, McGuffin $\mathrm{P}$, Owen $\mathrm{M}$, Ollier W, Worthington J, Gill M, Kirley A, Hawi Z, Fitzgerald M, Asherson P, Curran S, Mill J, Gould A, Taylor E, Kent L, Craddock N, Thapar A (2002) Association of DRD4 in children with ADHD and comorbid conduct problems. Am J Med Genet B: Neuropsychiatr Genet 114:150-153

19. Holmes J, Payton A, Barrett JH, Hever T, Fitzpatrick H, Trumper AL, Harrington $\mathrm{R}$, McGuffin $\mathrm{P}$, Owen $\mathrm{M}$, Ollier W, Worthington J, Thapar A (2000) A family-based and case-control association study of the dopamine D4 receptor gene and dopamine transporter gene in attention deficit hyperactivity disorder. Mol Psychiatry 5:523-530

20. Kuntsi J, Rijsdijk F, Ronald A, Asherson P, Plomin R (2005) Genetic influences on the stability of attentiondeficit/hyperactivity disorder symptoms from early to middle childhood. Biol Psychiatry 57:647-654

21. Langley K, Turic D, Peirce TR, Mills S, Van Den Bree MB, Owen MJ, O'Donovan MC, Thapar A (2005) No support for association between the dopamine transporter (DAT1) gene and ADHD. Am J Med Genet B Neuropsychiatr Genet 139:7-10

22. Larsson JO, Larsson $\mathrm{H}$, Lichtenstein $\mathrm{P}$ (2004) Genetic and environmental contributions to stability and change of ADHD symptoms between 8 and 13 years of age: a longitudinal twin study. J Am Acad Child Adolesc Psychiatry 43:1267-1275

23. Leibson CL, Long KH (2003) Economic implications of attention-deficit hyperactivity disorder for healthcare systems. Pharmacoeconomics 21:12391262

24. Li D, Sham PC, Owen MJ, He L (2006) Meta-analysis shows significant association between dopamine system genes and attention deficit hyperactivity disorder (ADHD). Hum Mol Genet 15:2276-2284

25. Lowe N, Kirley A, Hawi Z, Sham P, Wickham H, Kratochvil CJ, Smith SD, Lee SY, Levy F, Kent L, Middle F, Rohde LA, Roman T, Tahir E, Yazgan Y, Asherson P, Mill J, Thapar A, Payton A, Todd RD, Stephens T, Ebstein RP, 
Manor I, Barr CL, Wigg KG, Sinke RJ, Buitelaar JK, Smalley SL, Nelson SF, Biederman J, Faraone SV, Gill M (2004) Joint analysis of the DRD5 marker concludes association with attentiondeficit/hyperactivity disorder confined to the predominantly inattentive and combined subtypes. Am J Hum Genet 74:348-356

26. Maher BS, Marazita ML, Ferrell RE, Vanyukov MM (2002) Dopamine system genes and attention deficit hyperactivity disorder: a meta-analysis. Psychiatr Genet 12:207-215

27. Mill J, Caspi A, Williams BS, Craig I, Taylor A, Polo-Tomas M, Berridge CW, Poulton R, Moffitt TE (2006) Prediction of heterogeneity in intelligence and adult prognosis by genetic polymorphisms in the dopamine system among children with attention-deficit/hyperactivity disorder: evidence from 2 birth cohorts. Arch Gen Psychiatry 63:462469

28. Nadder TS, Rutter M, Silberg JL, Maes HH, Eaves LJ (2002) Genetic effects on the variation and covariation of attention deficit-hyperactivity disorder (ADHD) and oppositional-defiant disorder/conduct disorder (Odd/CD) symptomatologies across informant and occasion of measurement. Psychol Med 32:39-53
29. Price TS, Simonoff E, Asherson P, Curran S, Kuntsi J, Waldman I, Plomin $\mathrm{R}$ (2005) Continuity and change in preschool ADHD symptoms: longitudinal genetic analysis with contrast effects. Behav Genet 35:121-132

30. Purper-Ouakil D, Wohl M, Mouren MC, Verpillat P, Ades J, Gorwood P (2005) Meta-analysis of family-based association studies between the dopamine transporter gene and attention deficit hyperactivity disorder. Psychiatr Genet 15:53-59

31. Rietveld MJ, Hudziak JJ, Bartels M, van Beijsterveldt CE, Boomsma DI (2004) Heritability of attention problems in children: longitudinal results from a study of twins, age 3-12. J Child Psychol Psychiatry 45:577-588

32. Shaw P, Gornick MC, Lerch JP, Addington AM, Seal J, Greenstein DK, Sharp W, Evans AC, Giedd JN, Castellanos FX, Rapoport JL (2007) Polymorphisms of the dopamine D4 receptor, clinical outcome and cortical structure in attention-deficit/hyperactivity disorder. Arch Gen Psychiatry 648:921-931

33. Sherrington R, Mankoo B, Attwood J, Kalsi G, Curtis D, Buetow K, Povey S, Gurling H (1993) Cloning of the human dopamine D5 receptor gene and identification of a highly polymorphic microsatellite for the DRD5 locus that shows tight linkage to the chromosome $4 \mathrm{p}$ reference marker RAF1P1. Genomics 18:423-425
34. Thapar A, Langley K, Asherson P, Gill M (2008) Gene-environment interplay in ADHD and the importance of a developmental perspective. Br J Psychiatry (in press)

35. Thapar A, O’Donovan M, Owen MJ (2005) The genetics of attention deficit hyperactivity disorder. Hum Mol Genet 14(Spec No. 2):R275-R282

36. Wang E, Ding YC, Flodman P, Kidd JR, Kidd KK, Grady DL, Ryder OA, Spence MA, Swanson JM, Moyzis RK (2004) The genetic architecture of selection at the human dopamine receptor D4 (DRD4) gene locus. Am J Hum Genet 74:931-944

37. Whittinger N, Langley $\mathrm{K}$, Fowler $\mathrm{T}$, Thomas H, Thapar A (2008) Clinical precursors of adolescent conduct disorder in children with attention-deficit hyperactivity disorder. J Am Acad Child Adolesc Psychiatry (in press)

38. Williams NM, Cardno AG, Murphy KC, Jones LA, Asherson P, McGuffin P, Owen MJ (1997) Association between schizophrenia and a microsatellite polymorphism at the dopamine D5 receptor gene. Psychiatr Genet 7:83-85 